\title{
XỬ LÝ ĐỒNG THỜI CÁC TRI ĐO GPS/GLONASS TRONG BÀI TOÁN NGHIÊN CỨU CHUYỂN DỊCH CỦA VỎ TRÁI ĐẤT
}

\author{
PGS. TSKH. HÀ MINH HÒA(1), PGS. TS. NGUYẼ̃N NGỌC LÂU ${ }^{(2)}$

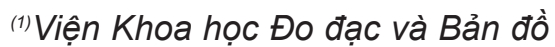 \\ ${ }^{(2)}$ Trường Đại học Bách khoa TP. Hồ Chí Minh
}

\section{Tóm tắt:}

Báo cáo khoa học này nêu lên những ưu điểm nổi bật của việc xử lý đồng thời các dữ liệu đo GPS/GLONASS trong việc giải quyết các nhiệm vu khoa học và kỹ thuật hiện đại của Trắc địa cao cấp. Điều này luận chứng cho ý nghĩa quan trọng của việc nghiên cứu và phát triển thành công phương pháp xử lý đồng thời các dữ liệu đo GPS/GLONASS trong công trình [4].

\section{1. Đặt vấn đề}

rong các tài liệu $[3,4]$ đã chỉ ra rằng Ttrong các kết quả đo đồng thời $\perp$ GPS/GLONASS, các kết quả đo GLONASS đóng vai trò các trị đo dư. Do đó khi xử lý đồng thời các dữ liệu đo GPS/GLONASS trong Khung quy chiếu Quả đất quốc tế ITRF (International Terrestrial Reference Frame), độ chính xác xác định các vectơ baseline, các hiệu độ cao trắc địa tăng lên $\sqrt{2}$ lần. Đây là cơ sở để hoàn thiện Khung quy chiếu không gian quốc gia SSRF (State Spatial Reference Frame) gắn với việc xây dựng mô hình Quasigeoid độ chính xác cao trên lãnh thổ quốc gia. Kết luận nêu trên đã được khẳng định nhờ kết quả nghiên cứu phát triển phần mềm GUST Ver.2 để xử lý đồng thời các dữ liệu đo GPS/GLONASS và thực nghiệm trên mạng lưới GNSS Sông Mã trong đề tài nghiên cứu khoa học [4]. Trong tài liệu [2] đã xác định được yêu cầu mật độ các điểm GPS của mạng lưới trắc địa địa động lực phục vụ nghiên cứu chuyển dịch của vỏ Trái đất khi cho trước các yêu cầu độ chính xác xác định các tham số chuyển dịch (ngang, đứng) và yêu cầu xử lý các dữ liệu đo GPS trong ITRF. Vậy nẩy sinh một loạt câu hỏi:

- Khi đo đạc đồng thời GPS/GLONASS trên các điểm GNSS (Global Navigation Satellite System) của mang lưới trắc địa địa động lực, với các yêu cầu độ chính xác xác định các tham số chuyển dịch (ngang, đứng) cho trước và yêu cầu xử lý các kết quả đo GPS/GLONASS trong ITRF, khoảng cách tối đa giữa các điểm GNSS là bao nhiêu?.

- Với khoảng cách tối đa giữa các điểm GNSS cho trước, việc đo đạc đồng thời GPS/GLONASS trên các điểm GNSS của mạng lưới trắc địa địa động lực và xử lý các kết quả đo này trong ITRF, độ chính xác xác định các tham số chuyển dịch sẽ đạt giá trị nào?.

Việc giải đáp các câu hỏi nêu trên là một trong những cơ sở quan trọng để thiết kế mạng lưới trắc địa địa động lực cạnh dài phục vụ nghiên cứu chuyển dịch các mảng kiến tạo hoặc mạng lưới địa động lực phục vụ nghiên cứu chuyển dịch của các đới đứt gãy. Đây cũng là nội dung nghiên cứu của báo cáo khoa học này.

Người phản biện: TS. Nguyễn Đình Thành 


\section{Giải quyết vấn đề}

Khi sử dụng lịch vệ tinh chính xác ở mức $5 \mathrm{~cm}$ trong ITRF đối với cả vệ tinh GPS lẫn vệ tinh GLONASS, theo kết quả nghiên cứu trong tài liệu [2], sai số trung phương của chiều dài cạnh $S$ được xác định bằng công nghệ GNSS được biểu diễn dưới dạng:

$$
\mathrm{m}_{\mathrm{S}}=2,5 \times 10^{-9} \times \mathrm{S} \text {. }
$$

Công thức (1) được áp dụng đối với trường hợp xử lý riêng rẽ các trị đo GPS và GLONASS. Giả thiết rằng trong các dữ liệu đo đồng thời GPS/GLONASS. Khi đó lưu ý công thức (1) chúng ta sẽ xác định được công thức của sai số trung phương đo cạnh $S$ trong kết quả xử lý đồng thời các dữ liệu đo GPS/GLONASS:

$$
m_{\bar{S}}=1,8 \cdot 10^{-9} . S .
$$
hợp.

Bây giờ chúng ta sẽ xem xét hai trường

Trường hợp 1: Cho trước tốc độ thay đổi nhỏ nhất $\mathrm{V}$ của thành phần tọa độ, độ cao. Xác định khoảng cách tối đa giữa các điểm GNSS trong mạng lưới địa động lực.

Như đã chứng minh trong tài liệu [2], khi nghiên cứu chuyển dịch theo phương pháp tương đối, sai số trung phương cho phép $\mathrm{m}_{\mathrm{cp}}$ của một thành phần hiệu tọa độ phẳng, hiệu độ cao trắc địa giữa hai điểm GNSS được xác định theo công thức:

$$
m_{c p} \leq \frac{V}{3 \cdot \sqrt{2}} .
$$

Khi nghiên cứu chuyển dịch đứng theo phương pháp tương đối dựa trên hiệu của các hiệu độ cao trắc địa cùng tên của một cạnh được xác định trong 2 chu kỳ đo lặp, với yêu cầu xác định tốc độ chuyển dịch đứng $V$ nhỏ nhất bằng $3 \mathrm{~mm} / 1$ năm, từ công thức (3) chúng ta thấy rằng sai số trung phương lớn nhất xác định hiệu độ cao trắc địa giữa hai điểm bằng $\mathrm{m}_{\mathrm{LH}}=0,7 \mathrm{~mm}$.
Mặt khác theo tài liệu [1] sai số trung phương của hiệu độ cao trắc địa giữa hai điểm GNSS nhận được trong kết quả bình sai mạng lưới GNSS được đánh giá theo công thức:

$$
m_{\Delta H}=\frac{m_{S}}{3} .
$$

Khi xử lý các kết quả đo đồng thời GPS/GLONASS trong ITRF, lưu ý công thức (2) chúng ta có công thức đánh giá sai số trung phương của hiệu độ cao trắc địa giữa hai điểm GNSS

$$
m_{\Delta H}=0,6 \cdot 10^{-9} . S .
$$

Với $\mathbf{m}_{\mathrm{LH}}=0,7 \mathrm{~mm}$ từ công thức (4) chúng ta thấy rằng chiều dài lớn nhất giữa hai điểm GNSS kề nhau có thể đạt tới 1170 $\mathrm{km}$. Tất nhiên khoảng cách giữa hai điểm GNSS càng ngắn hơn so với giới hạn trên, độ chính xác xác định tốc độ chuyển dịch đứng sẽ càng cao hơn. Trong trường hợp xử lý riêng rẽ dữ liệu đo GPS, chiều dài lớn nhất giữa hai điểm GPS kề nhau chỉ có thể cho phép đến $840 \mathrm{~km}$.

Khi nghiên cứu xác định chuyển dịch ngang của vỏ Trái đất với tốc độ chuyển dịch theo một trục tọa độ (x hoặc $y$ ) nhỏ nhất $\mathrm{V}=5 \mathrm{~mm} / 1$ năm, dựa vào công thức (3) sai số trung phương của hiệu các tọa độ phẳng giữa hai điểm được đánh giá bằng $m_{\Delta x}=m_{\Delta y}=0,7 \mathrm{~mm}$. Mặt khác do các sai số trung phương của hiệu các tọa độ phẳng giữa hai điểm được đánh giá theo công thức

$$
m_{\Delta x}=m_{\Delta y}=\frac{m_{S}}{\sqrt{2}},
$$

nên trong trường hợp xử lý đồng thời các kết quả đo GPS/GLONASS trong ITRF, Iưu ý công thức (2) chúng ta có:

$$
m_{\Delta x}=m_{\Delta y}=1,3 \cdot 10^{-9} . S .
$$


Với yêu cầu $m_{\Delta x}=m_{\Delta y}=0,7 \mathrm{~mm}$. từ công thức (5) chúng ta thấy rằng chiều dài lớn nhất giữa hai điểm GNSS kề nhau có thể đạt tới $540 \mathrm{~km}$. Đối với trường hợp xử lý riêng rẽ trị đo GPS chiều dài lớn nhất giữa hai điểm GPS kề nhau chỉ có thể cho phép đến $400 \mathrm{~km}$.

Như vậy trong trường hợp đang xem xét, việc xử lý đồng thời các kết quả đo GPS/GLONASS trên mạng lưới GNSS địa động lực cho phép tăng chiều dài giữa các điểm GNSS kề nhau. Điều này phản ánh tính ưu việt hơn của việc xử lý đồng thời các kết quả đo GPS/GLONASS trên mạng lưới GNSS địa động lực trong nghiên cứu chuyển dịch các mảng kiến tạo so với trường hợp chỉ xử lý các kết quả đo GPS (hoặc GLONASS).

Trường hợp 2: Cho trước khoảng cách lớn nhất giữa các điểm GNSS trong mạng lưới địa động lực. Đánh giá tốc độ chuyển dịch nhỏ nhất có thể phát hiện được nhờ xử lý đồng thời các kết quả đo GPS/GLONASS

Theo tài liệu [5], trên khu vực đới đứt gãy sự uốn cong đàn hồi thâm nhập vào các khối đất đá tiếp xúc đến $10-15 \mathrm{~km}$, tức chiều rộng của vùng tích lũy độ cong đàn hồi khoảng $20-50 \mathrm{~km}$. Do đó trong thực tế xây dựng mạng lưới GNSS để nghiên cứu chuyển dịch của vỏ Trái đất trên khu vực đứt gãy, khoảng cách lớn nhất giữa các điểm GNSS thường không lớn hơn 100 km. Khi nhận $S=100$ km, lưu ý các công thức (3) và (5) chúng ta thấy rằng trong trường hợp xử lý đồng thời các kết quả đo GPS/GLONASS trên mạng lưới địa động lực, chúng ta có thể xác định được tốc độ chuyển dịch ngang nhỏ nhất theo mỗi trục tọa độ ở mức $V_{\Delta x, \Delta y}=0,6 \mathrm{~mm}$. Tương tự trong trường hợp trên khi nhận $S=100 \mathrm{~km}$ và lưu ý các công thức (3), (4) chúng ta có thể xác định chuyển dịch đứng nhỏ nhất ở mức $V_{H}=0,3$ $\mathrm{mm}$. Điều này cho thấy ưu điểm nổi bật của việc xử lý đồng thời các kết quả đo GPS/GLONASS trên mạng lưới địa động lực phục vụ nghiên cứu chuyển dịch của vỏ Trái đất. Như vậy các độ chính xác nghiên cứu chuyển dịch ngang và đứng là cao hơn rất nhiều so với yêu cầu xác định các vectơ chuyển dịch vỏ Trái đất.

Các kết quả nghiên cứu trong tài liệu [4] cho thấy rằng các độ chính xác của các vectơ baseline trong các trường hợp xử lý riêng rẽ các trị đo GPS và GLONASS là tương đương nhau. Do đó khi yêu cầu xác định các vectơ chuyển dịch ngang và đứng trên khu vực đứt gãy ở mức một vài mm, việc đo đạc và xử lý đồng thời các kết quả đo GPS/GLONASS trên mạng lưới GNSS địa động lực cho phép giảm 2 lần số ca đo 24 h cần thiết. Hiện nay với 32 vệ tinh GPS và 26 vệ tinh GLONASS trên bầu trời và với các máy thu GPS/GLONASS hai tần số như R4, R5, R6, R7, R8 của Hãng TRIMBLE, GRX1 của Hãng SOKKIA v...v, chúng ta hoàn toàn có thể thu đồng thời các dữ liệu đo GPS/GLONASS. Do đó việc giảm khối lượng đo đạc vệ tinh là ưu điểm cơ bản của việc ứng dụng phương pháp đo đạc và xử lý đồng thời các dữ liệu đo GPS/GLONASS trong nghiên cứu chuyển dịch của vỏ Trái đất.

\section{Kết luận}

Với việc coi các dữ liệu đo GLONASS là các dữ liệu đo dư trong mạng lưới GNSS, việc xử lý đồng thời các dữ liệu đo GPS/ GLONASS có những ưu điểm nổi bật như làm tăng độ chính xác của độ cao trắc địa 
và qua đó làm nâng cao độ chính xác xác định dị thường độ cao trong bài toán xây dựng mặt Quasigeoid độ chính xác cao trên lãnh thổ quốc gia, nâng cao độ chính xác của việc xác định các tham số và giảm khối lượng đo đạc vệ tinh trong bài toán nghiên cứu chuyển dịch của vỏ Trái đất trên khu vực đứt gãy. Các kết luận nêu trên góp phần quan trọng trong việc định hướng áp dụng công nghệ GNSS để giải quyết các bài toán hiện đại của Trắc địa động lực (Dynamic Geodesy) và Trắc địa động (Kinematic Geodesy) ở Việt Nam./.O

\section{Tài liệu tham khảo}

[1]. Hà Minh Hòa (2002). Nghiên cứu cơ sở đánh giá ước tính độ chính xác hiệu độ cao trắc địa được xác định theo công nghệ GPS trên các khoảng cách khác nhau. Báo cáo khoa học. Quyển 5: Trắc địa - Địa chính - Bản đồ. Hội nghị khoa học lần thứ 15 , trường Đại học Mỏ - Địa chất Hà Nội, tháng 11 - 2002, trg. 35-37.

[2]. Hà Minh Hòa (2006). Một số vấn đề liên quan đến thiết kế mạng lưới GPS địa động lực trong bài toán nghiên cứu chuyển dịch của vỏ Trái đất trên khu vực đứt gãy phục vụ công tác dự báo tai biến tự nhiên. Tạp chí Địa chính, No4, tháng 8 - 2006, trg. $7-12$.

[3]. Hà Minh Hòa, Nguyễn Ngọc Lâu (2011). Vai trò của việc xử lý đồng thời các dữ liệu đo GPS/GLONASS trong ITRF để xác định dị thường độ cao độ chính xác cao. Tạp chí Khoa học Đo đạc và Bản đồ, No8, thánh 6 - 2011, trg. 1-6.

[4]. Hà Minh Hòa, Nguyễn Ngọc Lâu, Lưu Hải Âu, Nguyễn Thị Thanh Hương (2011). Nghiên cứu phương pháp xử lý đồng thời các dữ liệu đo GPS/GLONASS để đồng bộ dị thường độ cao vệ tinh - thủy chuẩn và dị thường độ cao trọng lực trong bài toán xác định mặt Geoid. Đề tài nghiên cứu khoa học và công nghệ cấp Bộ Tài nguyên và Môi trường. Hà Nội, Tháng 5/2011.

[5]. Pevnev A.K. (1997). Vị trí của Trắc địa trong vấn đề dụ báo động đất. Matxcơva, XTNHIIGAiK. (Tiếng Nga). $O$

\section{Summary}

\section{GPS/GLONASS mixed processing in task of earth crustall movement estimation}

Assoc. Prof. Dr. Sc. Ha Minh Hoa

Vietnam Institute of Geodesy and Cartography

Assoc. Prof. Dr. Nguyen Ngoc Lau

Hochiminh City University of Technology

This scientific report describes stad - out advantages of the mixed GPS/GLONASS processing for solving modern science - technical tasks of the High Geodesy. That proves important signification of the research and successful development of the mixed GPS/GLONASS processing in work [4].O

Ngày nhận bài: 18/6/2013. 